\title{
IL2RA Allele Increases Risk of Neuromyelitis Optica in Southern Han Chinese
}

\author{
Yongqiang Dai, Jin Li, Xiaonan Zhong, Yuge Wang, Wei Qiu, Zhengqi Lu, \\ Aimin Wu, Jian Bao, Fuhua Peng, Xueqiang $\mathrm{Hu}$
}

\begin{abstract}
Background: Neuromyelitis optica (NMO) and multiple sclerosis (MS) are chronic neuro-inflammatory diseases believed to arise from complex interactions between environmental and genetic factors. Recently, single nucleotide polymorphisms (SNPs) in interleukin (IL)-2 and -7 receptor alpha genes have been identified as novel susceptibility alleles for MS in genome-wide association studies. However, similar research on NMO is limited. We aimed to investigate the association of IL2RA SNPs rs2104286 and rs12722489 and IL7RA SNP rs6897932 with Southern Han Chinese NMO and MS patients. Methods: Frequencies of the three SNPs were examined in Southern Han Chinese MS cases $(n=78)$, NMO cases $(n=67)$ and controls $(n=133)$ using sequencing-based typing. Results: The $\mathrm{rs} 2104286^{\mathrm{G}}$ frequency in the $I L 2 R A$ gene was significantly higher in NMO patients than in controls $\left(p^{\text {uncorr }}=0.013\right.$, $p^{\text {corr }}=0.026$, OR:1.942, 95\%CI:1.146-3.291). Conclusion: The rs2104286 G allele in IL2RA is present at higher frequencies in NMO patients than in healthy controls within a Southern Han Chinese population.
\end{abstract}

RÉSUMÉ: Les allèles IL2RA augmentent le risque de neuromyélite optique chez les Chinois Han du sud. Contexte : La neuromyélite optique (NMO) et la sclérose en plaques (SP) sont des maladies neuroinflammatoires chroniques qu'on pense être dues à des interactions complexes entre des facteurs environnementaux et génétiques. Des polymorphismes d'un seul nucléotide (SNP) dans les gènes du récepteur alpha de l'interleukine 2 et de l'interleukine 7 ont été identifiés récemment par des études d'association pangénomiques comme étant des allèles de susceptibilité à la SP. Cependant, peu d'études semblables ont été faites sur la NMO. Le but de notre étude était d'examiner l'association des SNP rs2104286 et rs12722489 de IL2RA et le SNP rs6897932 de IL7RA chez des patients Chinois Han du sud atteints de NMO et de SP. Méthode : Nous avons examiné la fréquence des 3 SNP chez des Chinois Han du sud atteints de SP $(n=78)$, chez des patients atteints de NMO $(n=67)$ et chez des sujets témoins $(n=133)$ au moyen du typage par séquençage. Résultats : La fréquence de rs2104286G du gène IL2RA est significativement plus élevée chez les patients atteints de NMO que chez les témoins (p sans ajustement $=0,013, \mathrm{p}$ avec ajustement $=0,026 ; \mathrm{RC}: 1,942$; IC à 95\% : 1,146 à 3,291) Conclusion : La présence de l'allèle rs2104286G du gène IL2RA est plus fréquente chez les patients atteints de NMO que chez des témoins sains de la population chinoise Han du sud.

Can J Neurol Sci. 2013; 40: 832-835

Neuromyelitis optica (NMO) and multiple sclerosis (MS) are chronic neuroinflammatory diseases that are believed to arise from complex interactions between environmental and genetic factors. ${ }^{1,2}$ The association of the human leucocyte antigen (HLA) loci in MS has been extensively studied and is estimated to account for $20-60 \%$ of genetic susceptibility in MS. Within this locus, the HLA-DRB1*1501 allele is most strongly associated with MS in Caucasian populations. ${ }^{3,4}$ However, the lower incidence of NMO compared with MS has resulted in fewer studies on HLA genes in NMO patients. ${ }^{5}$ Several small-sample studies showed that the HLA-DPB $1 * 0501$ allele might increase the NMO risk in Asian populations, ${ }^{2,6,7}$ although a number of non-HLA single nucleotide polymorphisms (SNPs) have also been evaluated for their role in MS (and opticospinal MS (OSMS)/NMO) in Asians as the HLA association only explains some of the genetic impact on disease susceptibility. ${ }^{8-13}$

In 2007, the first large-scale genome wide association study (GWAS) of MS reported three SNPs to be associated with MS: two in the IL2RA gene (rs2104286 and rs12722489) and one in IL7RA (rs6897932). ${ }^{14}$ These results were also replicated in later studies. ${ }^{15,16} I L 2 R A$ and IL7RA encode the alpha chain of interleukin (IL) 2 and IL7 receptors, respectively, which are involved in $\mathrm{T}$ cell regulation. A major function of the IL2/IL2RA axis is to promote the proliferation and expansion of antigenspecific $\mathrm{CD}^{+}$and $\mathrm{CD}^{+} \mathrm{T}$ cell clones, while the IL7/IL7RA interaction maintains memory $\mathrm{T}$ cells and is involved in the development, proliferation and survival of $\mathrm{B}$ and T cells. ${ }^{17,18}$

Variations in IL2RA and IL7RA are also associated with other autoimmune diseases such as type I diabetes, Graves' disease and rheumatoid arthritis. ${ }^{19-22}$ Recently, Fang et al investigated

\footnotetext{
From the Department of Neurology, the Third Affiliated Hospital of Sun Yat-Sen University, Guangzhou, Guangdong Province, China.

Received January 8, 2013. Final Revisions Submitted May 8, 2013. Correspondence to: Xueqiang Hu, Department of Neurology, the Third Affiliated Hospital of Sun Yat-Sen University, Guangzhou, Guangdong Province 510630, China. Email: huxueqiangzssy@yahoo.com.cn.
} 
the association of the IL7RA SNP rs6897932 with MS and NMO Japanese patients and found that this allele appears to increase the risk of MS but not NMO.$^{23}$ However, it remains unknown whether these IL2RA and IL7RA SNPs are associated with NMO in the Han Chinese population. In this study, therefore, we genotyped SNPs rs2104286, rs12722489 and rs6897932 in MS and NMO patients and healthy controls from a Han Chinese population, and discuss their susceptibility risk.

\section{Materials ANd Methods}

\section{Patients and controls}

Seventy-eight AQP4-Ab-negative relapsing-remitting MS (RRMS) patients (53 women, 25 men) fulfilling the 2005 McDonald criteria ${ }^{23}$ and 67 AQP4-Ab-positive NMO patients (51 women, 16 men) based on the 2006 Wingerchuk diagnostic criteria $^{24}$ were recruited for this study. The mean age of disease onset was 30.26 years for MS patients and 34.37 years for NMO. One hundred and thirty-three unrelated healthy people with no first-degree relative with an autoimmune disease were recruited as controls (95 women, 38 men; mean age, 34.14 years). All subjects were Southern Han Chinese and were born in southern China.

All patients were examined thoroughly in the neurology department of the Third Affiliated Hospital of Sun Yat-sen University, Guangzhou, China. Indirect immunofluorescence was used to detect human AQP4-Ab (EUROIMMUN, Lübeck,
Germany) according to the manufacturer's instructions. This study was approved by the Ethics Committee of the Third Affiliated Hospital of Sun Yat-sen University.

\section{Genotyping}

Peripheral blood samples were collected from all subjects and stored at $-20^{\circ} \mathrm{C}$. Genomic DNA was extracted using the Tianamp N96 DNA Blood Kit (Tiangen, Beijing, China) and the SNPs were amplified by polymerase chain reaction (PCR) using the following primers: rs2104286 forward primer 5'ATGAGCGACATAGTCCTGAT-3' and reverse primer 5'GGTTGCAGTGAGTTGAGATT-3'; rs12722489 forward primer 5'- GTCCATCGTGCCGTTCTTAT-3' and reverse primer 5'-TTCTCCTCCTCACCAGGTTA-3'; rs6897932 forward primer 5'-CCACTGCATGGCTACT GAAT -3' and reverse primer 5' - ACAGGCCAAGATGACCAACA -3'. Polymerase chain reaction amplification was performed using 50 ng genomic DNA in a $20 \mu \mathrm{l}$ reaction mixture containing $20 \mathrm{mM}$ Tris- $\mathrm{HCl} \mathrm{pH}$ 8.0, $50 \mathrm{mM}$ EDTA, $0.2 \mathrm{mM}$ dNTPs, $1.5 \mathrm{mM}$ $\mathrm{MgCl}_{2}, 0.5 \mu \mathrm{mol}$ each forward and reverse primers, and 2.5 units of Taq polymerase. Cycle conditions consisted of 30 cycles of $95^{\circ} \mathrm{C}$ for five minutes (min), denaturation at $94^{\circ} \mathrm{C}$ for one min, annealing at $56^{\circ} \mathrm{C}$ for one min, and extension at $72^{\circ} \mathrm{C}$ for one min, followed by a final extension at $72^{\circ} \mathrm{C}$ for seven min. Polymerase chain reaction products were $480 \mathrm{bp}$ in size. After standardisation of the PCR conditions, sequencing was carried

Table: Genotype and allele distribution of the SNPs in patients and controls

\begin{tabular}{|c|c|c|c|}
\hline & $\operatorname{MS}(n=78)$ & NMO $(n=67)$ & Controls $(n=133)$ \\
\hline \multicolumn{4}{|l|}{ rs6897932 } \\
\hline \multicolumn{4}{|l|}{ Genotypes } \\
\hline $\mathrm{CC}$ & $52(66.7 \%)$ & $47(70.1 \%)$ & $90(67.7 \%)$ \\
\hline $\mathrm{CT}$ & $16(20.5 \%)$ & $12(17.9 \%)$ & $27(20.3 \%)$ \\
\hline TT & $10(12.8 \%)$ & $8(11.9 \%)$ & $16(12.0 \%)$ \\
\hline \multicolumn{4}{|l|}{ Alleles } \\
\hline $\mathrm{C}$ & $120(76.9 \%)$ & $106(79.1 \%)$ & $207(77.8 \%)$ \\
\hline $\mathrm{T}$ & $36(23.1 \%)$ & $28(20.9 \%)$ & $59(22.2 \%)$ \\
\hline \multicolumn{4}{|c|}{ rs12722489 } \\
\hline \multicolumn{4}{|l|}{ Genotypes } \\
\hline AA & $3(3.8 \%)$ & $1(1.5 \%)$ & $2(1.5 \%)$ \\
\hline $\mathrm{AG}$ & $24(30.8 \%)$ & $23(34.3 \%)$ & $40(30.0 \%)$ \\
\hline GG & $51(65.4 \%)$ & $43(64.2 \%)$ & $91(68.4 \%)$ \\
\hline \multicolumn{4}{|l|}{ Alleles } \\
\hline G & $126(80.8 \%)$ & $109(81.3 \%)$ & $222(83.5 \%)$ \\
\hline A & $30(19.2 \%)$ & $25(18.7 \%)$ & $44(16.5 \%)$ \\
\hline \multicolumn{4}{|l|}{ rs2104286 } \\
\hline \multicolumn{4}{|l|}{ Genotypes } \\
\hline AA & $57(73.1 \%)$ & $39(58.2 \%)$ & $98(73.7 \%)$ \\
\hline AG & $18(23.1 \%)$ & $24(35.8 \%)$ & $33(24.8 \%)$ \\
\hline GG & $3(3.8 \%)$ & $4(6.0 \%)$ & $2(1.5 \%)$ \\
\hline \multicolumn{4}{|l|}{ Alleles } \\
\hline $\mathrm{A}$ & $132(84.6 \%)$ & $102^{\mathrm{a}}(76.1 \%)$ & $229^{\mathrm{a}}(86.1 \%)$ \\
\hline $\mathrm{G}$ & $24(15.4 \%)$ & $32^{\mathrm{a}}(23.9 \%)$ & $37^{\mathrm{a}}(13.9 \%)$ \\
\hline
\end{tabular}

${ }^{\text {a }} P^{\text {uncorr }}<0.01, P^{\text {corr }}<0.05$, OR:1.942, 95\%CI:1.146-3.291. NMO: Neuromyelitis optica; MS: Multiple sclerosis 
out using an automated DNA sequencer ABI Prism 3700 (Applied Biosystems, Foster City, CA). Genotyping was deemed successful if the concordance rate between duplicates was $\geq 95 \%$. For samples not showing a clear genotype, PCR and sequencing were repeated until the results were unequivocal.

\section{Statistical analyses}

The Hardy-Weinberg equilibrium (HWE) was initially determined and statistical analysis was carried out using SPSS 16.0 software (SPSS Inc, Chicago, IL). The Pearson chi-squared test or Fisher's exact test was used to compare genotype and allele frequencies between NMO or C-MS patients and controls. Relative risk (estimated as the odds ratios, ORs) and 95\% confidence intervals $(95 \% \mathrm{CIs}$ ) were calculated. $P$ values (uncorrected $p, p^{\text {uncorr }}$ ) were corrected by Bonferroni-Dunn's correction to calculate corrected $p$ values $\left(p^{\text {corr }}\right)$. Statistical significance was set at $P<0.05$.

\section{RESULTS}

As shown in the Table, the G allele frequency of IL2RA SNP rs2104286 was significantly higher in NMO patients than controls $\quad\left(P^{\text {uncorr }}=0.013, P^{\text {corr }}=0.026\right.$, OR:1.942, 95\%CI:1.1463.291). There were no significant differences between the three groups for the IL2RA SNP rs12722489 and IL7RA SNP rs6897932.

\section{DisCUSSION}

This study revealed a significant association of the IL2RA SNP rs2104286 with NMO in the Han Chinese population. No significant difference was found between NMO and MS patients and controls for the SNPs rs12722489 and rs6897932.

$I L 2 R A$ and IL7RA genes are involved in $\mathrm{T}$ cell regulation which plays an important role in the pathogenesis of autoimmune diseases besides MS and NMO ${ }^{19-22}$ Since the first GWAS in 2007 found a significant association between SNPs rs2104286, rs12722489 and rs6897932 with MS, this finding has been confirmed in several other Caucasian studies ${ }^{14-16}$ but has not been investigated in Asian patients until recently. In India, Lekha et al compared 15 non-HLA SNPs in 197 MS patients and 197 healthy controls, and found that rs6897932 was the most associated SNP and that there was no significant association with rs2104286;18 rs12722489 was not examined in this study. In a Japanese study, Fang et al compared rs6897932 between 187 MS patients, $78 \mathrm{NMO}$ patients and 158 healthy controls and showed that the $\mathrm{C}$ allele and $\mathrm{CC}$ genotype frequencies were significantly higher in MS patients than controls. ${ }^{25}$ There was no significant difference between NMO patients and controls.

In the present study, we found that none of the three SNPs were associated with MS and that only rs2104286 was associated with NMO. We did not confirm that the rs6897932 SNP was associated with a MS or NMO risk. Previously, we reported that the HLA-DPB $1 * 0501$ allele increased the risk of NMO, but not MS. HLA-DRB1*1501, the allele most associated with MS in Caucasians, was not shown to be associated with MS and NMO.$^{26}$ Together, these results suggest that Han Chinese MS and NMO patients have a different genetic background to Caucasian and even other Asian patients in other countries. However, these results need to be confirmed in future studies.
Interleukin-2 has an important functional relevance in the proliferation of antigen-activated $\mathrm{T}$ cells. The IL-2 receptor alpha chain (also known as CD25) is mainly expressed in activated and regulatory $\mathrm{T}$ cells, and can increase the sensitivity of T cells to IL-2. Its expression is influenced by the SNP rs2104286 genotype. ${ }^{18,27}$ Although we showed that only the G allele of IL2RA SNP rs2104286 increases the risk of NMO in a Han Chinese population and not the other SNPs, which are known MS risk factors, the small sample size may have limited the power of the present study. Thus, larger cohort studies are required to confirm our findings and to further investigate CD25 expression associated with the rs2104286 genotype.

\section{REFERENCES}

1. Wang $\mathrm{H}$, Zhong $\mathrm{X}$, Wang $\mathrm{K}$, et al. Interleukin 17 gene polymorphism is associated with anti-aquaporin 4 antibodypositive neuromyelitis optica in the Southern Han Chinese--a case control study. J Neurol Sci. 2012;314(1-2):26-8.

2. Wang H, Dai Y, Qiu W, et al. HLA-DPB1 0501 is associated with susceptibility to anti-aquaporin-4 antibodies positive neuromyelitis optica in southern Han Chinese. J Neuroimmunol. 2011;233(1-2):181-4.

3. Haines JL, Terwedow HA, Burgess K, et al. Linkage of the MHC to familial multiple sclerosis suggests genetic hetero- geneity. The multiple sclerosis genetics group. Hum Mol Genet. 1998;7: 1229-34.

4. Ramagopalan SV, Ebers GC. Genes for multiple sclerosis. Lancet. 2008;371:283-5.

5. Wingerchuk DM. Diagnosis and treatment of neuromyelitis optica. Neurologist. 2007;13:2-11.

6. Yamasaki K, Horiuchi I, Minohara M, et al. HLA-DPB1*0501 associated optico-spinal multiple sclerosis: clinical, neuroimaging and immunogenetic studies. Brain. 1999;122: 1689-96.

7. Matsushita T, Matsuoka T, Isobe N, et al. Association of the HLADPB $1 * 0501$ allele with antiaquaporin-4 antibody positivity in Japanese patients with idiopathic central nervous system demyelinating disorders. Tissue Antigens. 2009;73:171-6.

8. Li K, Zhao B, Dai D, et al. A functional $\mathrm{p} .82 \mathrm{G}>\mathrm{S}$ polymorphism in the RAGE gene is associated with multiple sclerosis in the Chinese population. Mult Scler. 2011;17:914-21.

9. Fukazawa T, Kikuchi S, Miyagishi R, et al. CTLA-4 gene polymorphism is not associated with conventional multiple sclerosis in Japanese. J Neuroimmunol. 2005;159:225-9.

10. Osoegawa $\mathbf{M}$, Niino $\mathrm{M}$, Ochi $\mathrm{H}$, et al. Platelet-activating factor acetylhydrolase gene polymorphism and its activity in Japanese patients with multiple sclerosis. J Neuroimmunol. 2004;150: $150-6$.

11. Niino M, Kikuchi S, Fukazawa T, Yabe I, Sasaki H, Tashiro K. Genetic polymorphisms of IL-1beta and IL-1 receptor antagonist in association with multiple sclerosis in Japanese patients. J Neuroimmunol. 2001;118:295-9.

12. Rasmussen HB, Kelly MA, Francis DA, Clausen J. CTLA4 in multiple sclerosis. Lack of genetic association in a European Caucasian population but evidence of interaction with HLADR2 among Shanghai Chinese. J Neurol Sci. 2001;184:143-7.

13. Barcellos LF, Thomson G, Carrington M, et al. Chromosome 19 single-locus and multilocus haplotype associations with multiple sclerosis. Evidence of a new susceptibility locus in Caucasian and Chinese patients. JAMA. 1997;278:1256-61.

14. Hafler DA, Compston A, Sawcer S, et al. Risk alleles for multiple sclerosis identified by a genomewide study. N Engl J Med. 2007 Aug 30;357(9):851-62.

15. Gregory SG, Schmidt S, Seth P, et al; Multiple Sclerosis Genetics Group.Interleukin 7 receptor alpha chain (IL7R) shows allelic and functional association with multiple sclerosis. Nat Genet. 2007;39(9):1083-91. 
16. Weber F, Fontaine B, Cournu-Rebeix I, et al. IL2RA and IL7RA genes confer susceptibility for multiple sclerosis in two independent European populations. Genes Immun. 2008 Apr;9 (3):259-63.

17. Seddon B, Tomlinson P, Zamoyska R. Interleukin 7 and $\mathrm{T}$ cell receptor signals regulate homeostasis of CD4 memory cells. Nat Immunol. 2003 Jul;4(7):680-6.

18. Malek TR, Bayer AL. Tolerance, not immunity, crucially depends on IL-2. Nat Rev Immunol. 2004 Sep;4(9):665-74.

19. Qu HQ, Bradfield JP, Bélisle A, Grant SF, Hakonarson H, Polychronakos C. The type I diabetes association of the IL2RA locus. Genes Immun. 2009;10 Suppl 1:S42-8.

20. Brand OJ, Lowe CE, Heward JM, et al. Association of the interleukin-2 receptor alpha (IL-2Ralpha)/CD25 gene region with Graves' disease using a multilocus test and tag SNPs. Clin Endocrinol (Oxf). 2007;66(4):508-12.

21. Kurreeman FA, Daha NA, Chang M, et al. Association of IL2RA and IL2RB with rheumatoid arthritis: a replication study in a Dutch population. Ann Rheum Dis. 2009;68(11):1789-90.
22. Santiago JL, Alizadeh BZ, Martínez A, et al. Study of the association between the CAPSL-IL7R locus and type 1 diabetes. Diabetologia. 2008;51(9):1653-8.

23. Polman CH, Reingold SC, Edan G, et al. Diagnostic criteria for multiple sclerosis: 2005 revisions to the "McDonald Criteria". Ann Neurol. 2005;58:840-6.

24. Wingerchuk DM, Lennon VA, Pittock SJ, Lucchinetti CF, Weinshenker BG. Revised diagnostic criteria for neuromyelitis optica. Neurology. 2006;66:1485-1459.

25. Fang L, Isobe $\mathrm{N}$, Yoshimura $\mathrm{S}$, et al. Interleukin-7 receptor alpha gene polymorphism influences multiple sclerosis risk in Asians. Neurology. 2011;76(24):2125-7.

26. Pandit L, Ban M, Sawcer S, et al. Evaluation of the established nonMHC multiple sclerosis loci in an Indian population. Mult Scler. 2011;17(2):139-43.

27. Barton A, Woolmore JA, Ward D, et al. Association of protein kinase $\mathrm{C}$ alpha (PRKCA) gene with multiple sclerosis in a UK population. Brain. 2004;127:1717-22. 